\title{
SPOTLIGHT
}

\section{Climate change and resource security}

\author{
Climate change is a key issue for the future of the militaries of the UK and the US, says Neil \\ Morisetti, both in how they are run and what they are tasked to do
}

\section{Neil Morisetti rear admiral, UK government climate and energy security envoy}

Desk 6 G 20, Ministry of Defence Main Building, London SW1A 2HB, UK

There is a growing recognition that we face a number of new threats to global stability and national security. In particular, there are risks to secure, sustainable, and affordable supplies of key natural resources (food, water, and energy), essential for economic prosperity and wellbeing. The 2010 UK Strategic Defence and Security Review and the US Quadrennial Defence Review both highlighted the effects of climate change as one of these risks.

It is unlikely that climate change will be a direct cause of conflict. However, the impact of the second and third order consequences - loss of land or livelihood - has the potential to increase the risks of global instability and conflict in those parts of the world already experiencing other stresses, such as food or water shortages, health issues, or demographic challenges. Countries in this part of the world (centred on the equatorial belt) have experienced conflict in the past, both intrastate and interstate, frequently as a result of a lack of capacity in their government to look after the needs of their citizens. Because of this, climate change is widely recognised as a threat multiplier.

\section{Not somebody else's problem}

At a time when countries such as the United Kingdom, the wider European Union, and the United States face many other challenges, not least as a result of the global economic downturn, it is tempting to see this as somebody else's problem (especially when the direct impact of climate change in these countries is unlikely to be felt until much later in the 21 st century). However, by virtue of the globalised world that we live in, events many miles away can impact on the interests and security of our nations. A recent example of this is the impact felt by European and US companies as a result of the floods in Thailand. Whether it be auto parts or computer chips, both are manufactured in Thailand for subsequent use in the assembly of cars or computers in third party countries; the floods disrupted supplies and production lines had to be slowed. At the same time the loss of rice crops has resulted in shortages and price increases of this staple food product.
The problem is compounded in a "just enough, just in time" world where factory warehouses are on the high seas, on global trade routes passing through the parts of the world where climate change will have the greatest impact, and are therefore vulnerable to disruption. All nations are, to a greater or lesser extent, trading nations. In the case of the UK more than $90 \%$ of goods imported travel along these supply lines. Of particular concern for many countries is the risk to secure, sustainable, and affordable supplies of energy, key for economic growth and prosperity. This is not only an issue for Europe and America: $75 \%$ of China's oil comes from the Middle East via the Strait of Malacca. It is, therefore, in all our interests to address the risks posed by climate change. $\Downarrow$

\section{Time for a strategic view}

New threats and challenges frequently require governments, societies, and international institutions to adapt. Addressing climate change is no different. To tackle climate change nations will need to take a strategic approach; one which looks beyond the normal political and planning horizons, and one which involves all of government, as well as public and private collaboration, and international action. We should not focus only on the threats but also identify the opportunities, including that of economic growth.

The armed forces have a part to play in this process, both nationally and internationally, not least because we are part of society. We can contribute in several areas.

\section{What we can contribute-understanding}

Firstly, the armed forces can help in developing an understanding of the risks and how they will impact on both global stability and individual nations' interests. There is a need to improve our collective knowledge of how people in affected areas react to the loss of land or livelihood. Will they migrate or are they trapped? If they move will it be within their country or to another state? Will this migration be manageable or put 
further pressure on already stretched authorities? In the case of loss of livelihood, are there sufficient alternative and legitimate sources of income available, or are those affected susceptible to recruitment into serious crime or even paid terrorism?

Understanding these behaviours and the risks they pose is necessary to ensure that the threat of climate change is included in national security strategies and risk registers, and that it informs the priories for action, both adaptation and mitigation. Developing capacity in vulnerable countries, for example, is a key element of reducing the risk of conflict, as highlighted in the UK government's 2011 Building Stability Overseas Strategy, signed by the secretaries of state for Defence, Foreign Affairs, and International Development.

\section{Humanitarian assistance and disaster relief}

Secondly, analysis of risks and impacts can be used to establish likely future missions for the armed forces. One example is the provision of humanitarian assistance and disaster relief, something the armed forces frequently find themselves tasked to do. During the hurricane season the crew of the Royal Navy ship operating in the Caribbean is trained to perform such a role and is often called upon to do so. In the future, with the increased likelihood of extreme weather events, especially in the Indian Ocean and South East Asia, it may be necessary to have the same skills available in all deployed ships.

Both the Strategic Defence and Security Review and the Quadrennial Defence Review recognised that the military must retain the ability to provide conflict resolution but that there would also be greater involvement in the area of conflict prevention. That is not to say that the military will try to usurp the role of others, but will rather undertake complementary activity, such as developing the capacity of a country's coastguard to police its exclusive economic zone. The ability to work with other government departments, NGOs, and other organisations, is key to effectively delivering such activity, and these skills will need to be developed in advance, building on the experience gained in post-conflict stabilisation operations.

\section{Energy: from commodity to capability}

Finally, the armed forces need to make sure both that the mission can be delivered and that it can operate in a sustainable fashion. We must ensure that there are sufficient units available, such as helicopters for humanitarian assistance and disaster relief, and that they are capable of operating in harsher environments with potential water and energy shortages.

Fundamental to achieving this is addressing the use of energy. Energy has always been a critical enabler for the armed forces, whether it be fodder in Napoleon's time or diesel today. Like any other organisation the armed forces need an energy plan that recognises the requirement of obtaining secure, affordable, and sustainable supplies in order to deliver their outputs. At the same time they need to recognise that the manner in which they deliver that plan must address the requirement to reduce $\mathrm{CO}_{2}$ emissions, especially but not exclusively with regard to utility energy. Such an approach will address the challenges faced by the military when operating at great distance from their home bases, for example Iraq or Afghanistan. By changing behaviour, optimising existing equipment, and where appropriate using alternatives to fossil fuels (such as solar and wind) not only is it possible to reduce the cost and risk incurred in the supply chain but it will also help improve operational effectiveness. In the longer term it will be necessary to treat energy as a capability, rather than a commodity, and factor in the full costs throughout the projected life of the equipment. This can best be described as sustainable operational capability.

The military will always need a hard edged war fighting capability and will continue to use fossil fuels in the foreseeable future, but the choices that are made in delivering these capabilities must recognise the potential impact on the environment and on global stability.

NM is a serving officer in the Royal Navy with 36 years' experience. He acts as the UK Government's Climate and Energy Security Envoy. This article reflects current thinking on the potential security implications of climate change and action that needs to be taken to address the risks. NM is guarantor.

Competing interests: NM has completed the ICMJE uniform disclosure form at www.icmje.org/coi_disclosure.pdf (available on request from the corresponding author) and declares: no support from any organisation for the submitted work; no financial relationships with any organisations that might have an interest in the submitted work in the previous three years; and no other relationships or activities that could appear to have influenced the submitted work.

Provenance and peer review: Commissioned; not externally peer reviewed.

Accepted: 20 February 2012

Cite this as: BMJ 2012;344:e1352

๑ BMJ Publishing Group Ltd 2012 


\section{Figure}

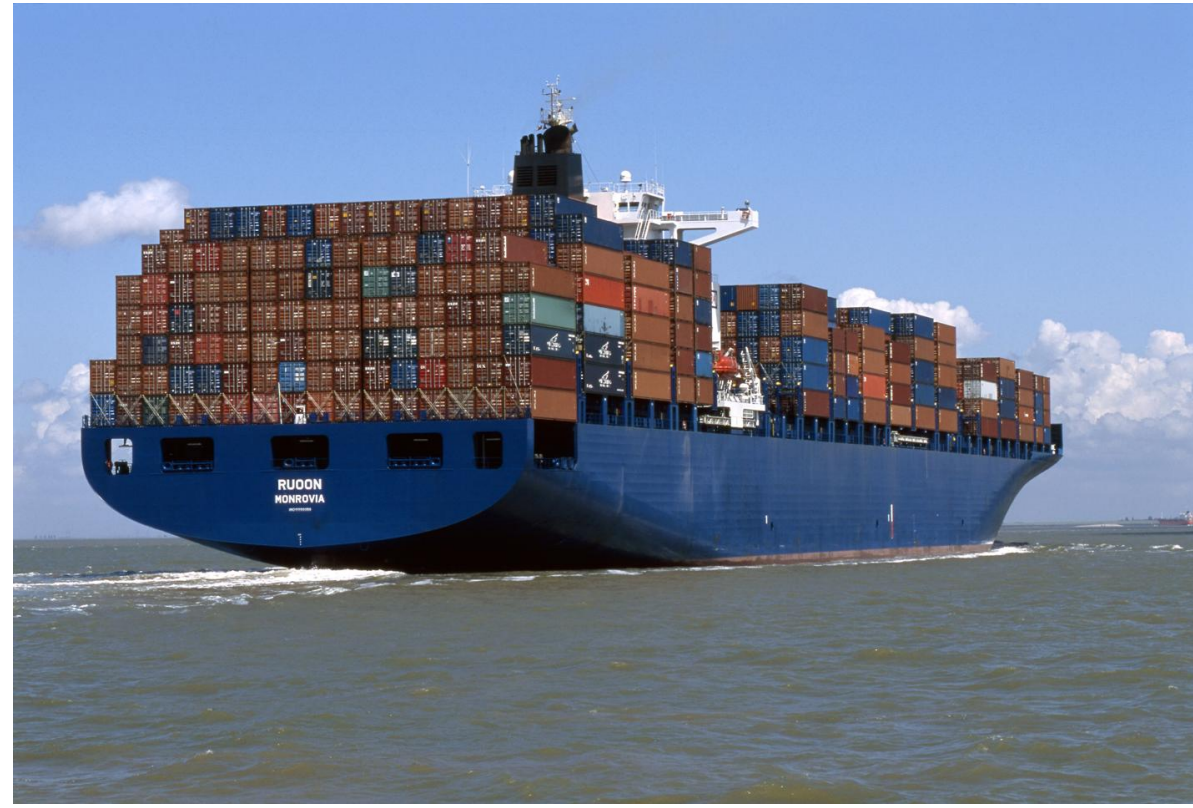

[IImage: DIRK WIERSMASSIENCE PHOTO LIBRARY] 